\title{
Effect of $\gamma$-alumina as active matrix added to HZSM-5 catalyst on the aromatization of methanol
}

\author{
Chen Chen ${ }^{1} \cdot$ Hongqiang $\mathrm{Ji}^{1} \cdot$ Qiang Zhang ${ }^{1} \cdot{\text { Chunyi } \mathrm{Li}^{1} \cdot \text { Honghong Shan }}^{1}$
}

Received: 31 July 2015/Accepted: 23 September 2015/Published online: 7 November 2015

(C) The Author(s) 2015. This article is published with open access at Springerlink.com

\begin{abstract}
HZSM-5-based catalyst is a recognized catalyst which is particularly selective towards the formations of aromatics in the methanol reaction. However, studies on HZSM-5-based catalyst were mainly focused on the addition of metallic or/and nonmetallic element. Quite few studies have reported the effect of active matrix such as $\gamma$ alumina on the aromatization of methanol. In this study, $\gamma$ alumina was introduced into HZSM-5-based catalyst for the purpose of investigating the effect of $\gamma$-alumina in methanol to aromatics reaction. The catalysts were characterized by $\mathrm{X}$-ray diffraction, Temperature-programmed Desorption of $\mathrm{NH}_{3}\left(\mathrm{NH}_{3}-\mathrm{TPD}\right)$, Pyridine adsorption FT-IR diffuse reflection spectroscopy and adsorption-desorption measurements of nitrogen, respectively. Characterizations showed that the introduction of $\gamma$-alumina increased the amount of mesopores and acid sites in the catalyst. The experimental mainly includes two parts. Firstly, separate reaction performances over the catalyst with/without $\gamma$ alumina and $\gamma$-alumina showed that $\gamma$-alumina could significantly promote the formations of aromatics. However, $\gamma$-alumina alone could merely convert methanol to dimethyl ether with a minor quantity of gaseous hydrocarbons. Acid properties showed that the introduction of $\gamma$-alumina increased the percentage of Lewis acid on catalyst surface and enhanced acid strength, as a result, promoted the production of active intermediates which was essential for aromatic formation. The rise of aromatics selectivity might
\end{abstract}

Qiang Zhang

girlzhangqiang@163.com

$\bowtie$ Chunyi Li

chyli@upc.edu.cn

1 State Key Laboratory of Heavy Oil Processing, China University of Petroleum, Qingdao 266580, China be caused by the combined effect of acid site density and acid strength. Follow-up work was mainly focused on the effect of the loading amount and loading order of the catalyst with $\gamma$-alumina. Results indicated that the total aromatic yield increased gradually with the increasing amount of catalyst with $\gamma$-alumina regardless of the loading order of the catalyst with $\gamma$-alumina. Gasoline compositions showed that the increased aromatics were at the expense of paraffins, olefins, and naphthenes. Besides, all single aromatic hydrocarbons increased gradually with the increasing amount of catalyst with $\gamma$-alumina. And the aromatics had a larger variation change when methanol first passed through the catalyst with $\gamma$-alumina.

Keywords Methanol $\cdot$ Aromatization $\cdot \gamma$-Alumina . Loading amount $\cdot$ Loading order

\section{Introduction}

Light aromatics, especially benzene, toluene, and xylene (BTX), are very important fundamental organic chemicals. Conventional BTX mainly originates from crude oil routes, such as catalytic reforming of naphtha and steam pyrolysis of naphtha [1]. However, so far, there has been a controversy existing especially in China, namely the shortage of crude oil and the increasing demand for BTX. In order to alleviate this severe situation, the conception of methanol to aromatic (MTA) via coal and natural gas routes has been put forward a few years ago, which was derived from the notion of methanol to gasoline (MTG) [2-5]. The most frequently employed active component for MTA is HZSM5 zeolite because of its peculiar three-dimensional network which is particularly selective towards the formation of aromatics [6-8]. After the proposal of MTA was lifted, 
many efforts have been made to investigate the MTA process with respecting to both reaction conditions and catalyst modifications. Among the studies conducted, researches on the modifications of HZSM-5 are dominant. And the most direct and simple method to modify catalyst was to introduce metallic or/and nonmetallic element onto HZSM-5 to enhance the yields of BTX and strengthen the stability of the catalyst. Previous researches [9-11] have demonstrated that silver modified HZSM-5 catalyst could significantly improve the aromatic selectivity among the hydrocarbons formed, but the catalyst was prone to undergo deactivation [12]. Likewise, gallium modified HZSM-5 catalyst also had a capability of considerably elevating the selectivity towards aromatics [13-16], however, due to its high price, gallium was not appropriate for commercial application. In addition, zinc modified HZSM5 catalyst was also widely reported in large numbers of papers [17-24], but the activity of the catalyst was unable to last long.

In contrast, quite few literatures have reported the effect of the addition of active matrix, such as $\gamma$-alumina, in the HZSM-5 catalyst on MTA. Although the functions of $\gamma-$ alumina in methanol reaction have been reported in several previous studies, their emphasis was simply focused on the crucial role of $\gamma$-alumina in the dehydration reaction of methanol into dimethyl ether (DME) [25-32]. According to above studies, the reaction of methanol could be promoted by $\gamma$-alumina, it was an intuitive guess that $\gamma$-alumina could facilitate the formation of aromatics from methanol. MTA is a complex process which includes a series of reactions, such as oligomerization, cracking, cyclization, and hydrogen transfer reaction. Cheng et al. have reported that Brönsted acid could contribute to the olefin oligomerization, cracking, cyclization, and hydrogen transfer reactions, while Lewis acid played a considerably important role in the dehydrogenation of alkanes and cycloalkene intermediates [19]. And it was generally known that there were large amounts of Lewis acid existed in the $\gamma$-alumina. Therefore, a reasonable conjecture can be made that the introduction of $\gamma$-alumina can adjust the Lewis acid/Brønsted acid ratio (L/B). As a result of combining the peculiar acidic property of $\gamma$-alumina and the capability for aromatization of HZSM-5 itself, MTA may get a significant promotion.

To investigate the effect of $\gamma$-alumina added into the catalyst composed of HZSM-5 in MTA, a series of experiments were performed in this study. In the first work, MTA reaction was carried out over the catalyst without $\gamma$ alumina, catalyst with $\gamma$-alumina, and $\gamma$-alumina alone, respectively. Then, two groups of experiments with a twolayer catalyst bed were conducted for the purpose of investigating the effect of the loading amount and loading order of the catalyst with $\gamma$-alumina in MTA.

\section{Experimental}

\section{Catalyst preparation}

The $\gamma$-alumina was achieved through sol-gel method using boehmite as raw material. The catalyst without $\gamma$-alumina, denoted as Catalyst I, was obtained by blending $30 \mathrm{wt} \%$ of HZSM-5 zeolite $\left(\mathrm{SiO}_{2} / \mathrm{Al}_{2} \mathrm{O}_{3}\right.$ ratio is 38 , Nankai University Catalyst Factory) with $5 \mathrm{wt} \%$ of silica (silica is in the form of silica sol) as binder and $65 \mathrm{wt} \%$ of kaolin as inert matrix. The catalyst with $\gamma$-alumina, denoted as Catalyst II, was prepared through the sol-gel method, in which $\gamma$-alumina was introduced as an active matrix and partly took the place of kaolin. The content of HZSM-5 zeolite in the Catalyst II was consistent with that in the Catalyst I. Then, after thorough stirring, $\gamma$-alumina, Catalyst I, and Catalyst II were all dried at $140{ }^{\circ} \mathrm{C}$ overnight and calcined at $700{ }^{\circ} \mathrm{C}$ in static air for $2 \mathrm{~h}$. After that, three kinds of catalysts were crushed and sieved to 80-180 mesh particles for later experiments.

\section{Catalyst characterization}

X-ray powder diffraction (XRD) patterns were recorded on an X'Pert PRO MPD diffractometer system using $\mathrm{Cu} \mathrm{K} \alpha$ radiation at $40 \mathrm{kV}$ and $40 \mathrm{~mA}$, running from $5^{\circ}$ to $75^{\circ}$ with a speed of $10^{\circ} / \mathrm{min}$. The type of the acid sites was measured by FT-IR spectra of pyridine adsorption with a Mercury Cadmm Telluride (MCT) detector using a Nexsus ${ }^{\text {TM }}$ FT-IR spectrometer. The spectra were recorded with $4 \mathrm{~cm}^{-1}$ and 64 scans. Textural properties were determined by adsorption-desorption measurements of nitrogen at liquid nitrogen temperature using a Quadrasorb SI instrument. Prior to the measurement, all samples were evacuated at $300{ }^{\circ} \mathrm{C}$ for $4 \mathrm{~h}$ at the pressure of $1.0 \times 10^{-3} \mathrm{kPa}$ so that the adsorbed moisture on the samples could be completely removed. And total acidity was obtained by Temperature-programmed Desorption of $\mathrm{NH}_{3}\left(\mathrm{NH}_{3}-\mathrm{TPD}\right)$. During the test, $0.1 \mathrm{~g}$ of sample was loaded into the apparatus, preheated in a flow of helium to $650{ }^{\circ} \mathrm{C}$ at which the treatment remained for $30 \mathrm{~min}$, and then cooled down to $100{ }^{\circ} \mathrm{C}$. Later, the catalyst was treated in a flow of $\mathrm{NH}_{3}$ for $30 \mathrm{~min}$ until the catalyst reached the top adsorption point. After the baseline went smoothly, the chemical desorption was carried out by heating the catalyst to $650{ }^{\circ} \mathrm{C}$ with a speed of $10^{\circ} \mathrm{C} / \mathrm{min}$.

\section{Reaction performance evaluation}

The experimental program was carried out in a continuous fixed bed microreactor of $15 \mathrm{~mm}$ i.d. and $24.5 \mathrm{~cm}$ length, which was manufactured by stainless steel (shown in Fig. 1), at $400{ }^{\circ} \mathrm{C}$ under atmospheric pressure with a fixed 


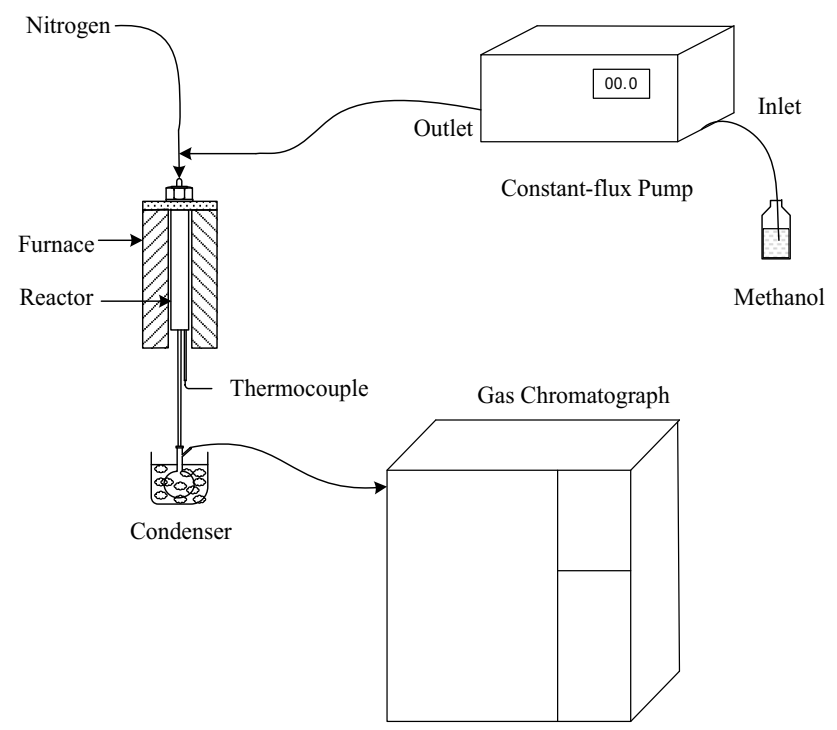

Fig. 1 Schematic of the reaction and analysis units

value of $3 \mathrm{~g}$ (mesh size: 80-180) of catalyst loaded at the bottom of the reactor. Prior to the reaction, the catalyst was degassed at reaction temperature in a nitrogen flow to remove the physical adsorbed water from the catalyst surface. During the reaction, pure methanol was fed into the reactor at a fixed flow rate of $0.4 \mathrm{~mL} / \mathrm{min}$ for $30 \mathrm{~min}$. After that, the reactor was purged with a nitrogen flow for $100 \mathrm{~s}$ in order to drive the residual products out of the reactor.

In this study, the experimental program mainly consisted of two parts. One part was carried out over the Catalyst I, Catalyst II, and $\gamma$-alumina, respectively. The other part was performed over a two-layer catalyst bed comprised the Catalyst I and Catalyst II for the purpose of investigating the loading amount and loading order of the HZSM-5 catalyst with $\gamma$-alumina. And the schematic of the catalyst loading is shown in Fig. 2. In the first group, the Catalyst I was in the upper with a loading amount of 0.5 ,
$1.0,1.5,2.0$, and $2.5 \mathrm{~g}$, respectively. Correspondingly, the loading amount of the Catalyst II in the lower was 2.5, 2.0, $1.5,1.0$, and $0.5 \mathrm{~g}$, respectively. Then in the other group, the filling order was reversed.

The effluent mainly encompassed four phase products which were gas phase, water phase, oil phase, and solid phase products. The compositions of gaseous products were analyzed by a Bruker 450 Gas Chromatograph equipped with a FID detector to determine the compositions of hydrocarbons and two TCD detectors to analyze the content of hydrogen, carbon monoxide, and carbon dioxide. The methanol content in the water phase was determined by an Agilent 6820 Gas Chromatograph with ethanol as the internal standard. The compositions of oil phase were confirmed by combination of a PerkinElmer PONA Gas Chromatograph to analyze the gasoline compositions and a Bruker 450 Simulated Distillation Gas Chromatograph according to the ASTM-2887 method to determine the gasoline and diesel contents. The solid product content, namely the amount of the coke deposited on the catalyst after reaction, was determined by analyzing the amount of the carbon oxide obtained from the burning of the coke using a TengHai 2000 Gas Chromatograph with $\mathrm{CaCO}_{3}$ as the contrast sample.

Correction factor for methanol, methanol conversion, and aromatic yield are calculated as follows:

correction factor for methanol

$$
\begin{aligned}
=\frac{m_{\text {methanol }} \times S_{\text {ethanol }}}{m_{\text {ethanol }} \times S_{\text {methanol }}} & \times 100 \mathrm{wt} \% \\
\text { methanol conversion }= & \frac{m_{\text {methanol,in }}-m_{\text {methanol,out }}}{m_{\text {methanol,in }}} \\
& \times 100 \mathrm{wt} \%
\end{aligned}
$$

aromatic yield $=\frac{m_{\text {gasoline }} \times S_{\text {aromatic } / \text { gasoline }}}{m_{\text {methanol,in }}} \times 100 \mathrm{wt} \%$
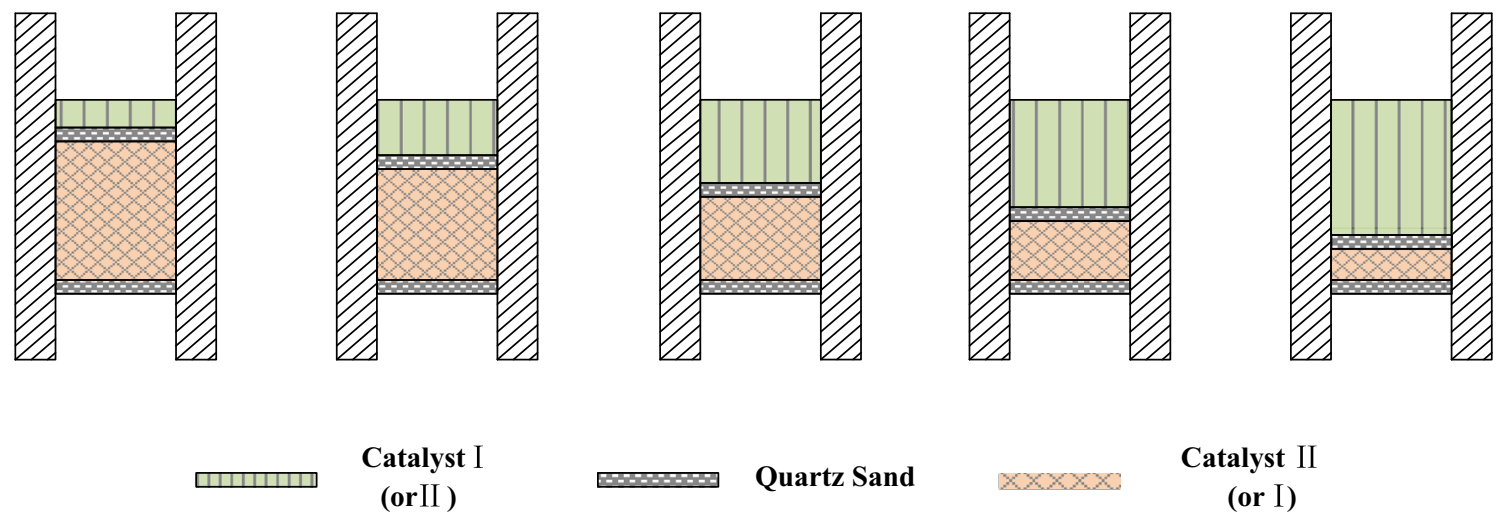

Fig. 2 Schematic of the catalyst loading 
$m_{\text {methanol }}$ and $m_{\text {ethanol }}$ were the masses added to the standard sample, $S_{\text {methanol }}$ and $S_{\text {ethanol }}$ were the peak areas obtained from the chromatograph.

\section{Results and discussion}

\section{Separate reaction performance of the Catalyst I, Catalyst II, and $\gamma$-alumina}

Reaction product distributions over the Catalyst I, Catalyst II, and $\gamma$-alumina, respectively, are listed in Table 1 . On the basis of Table 1, it could be seen that the pure methanol reacted at a nearly full conversion over both the Catalyst I and Catalyst II, while the conversion over the $\gamma$-alumina merely reached $83.33 \mathrm{wt} \%$. Different from the product distributions over the Catalyst I and Catalyst II, the primary products formed on the $\gamma$-alumina were DME accompanied by a minor quantity of gaseous hydrocarbons, which were in line with the previous literature that Lewis acid sites on the surface of $\gamma$-alumina only had effect on the dehydration of methanol and the dehydrogenation of intermediate products (such as alkane et al.) [33, 34]. As mentioned before, the combined effect of both Brönsted acid site and Lewis acid sites was an essential part in MTA reaction. Under the condition that no Brönsted acid site existed on the surface of $\gamma$-alumina, intermediates (such as alkane and light olefins) could not react easily to form aromatics. In addition, it could also be found that the yield of dry gas over the Catalyst II was lower than that over the Catalyst I, while the yields of liquefied petroleum gas (LPG), gasoline, diesel, and coke were relatively higher. Furthermore, it was very interesting to note that the yields of the light alkenes, such as ethene, propene, and butane over the Catalyst II were much lower compared with those over Catalyst I, which might result from the fact that light alkenes over the Catalyst II could further undergo a series of subsequent reactions, such as oligomerization, cyclization, and hydrogen transfer, more readily. It might be ascribed to the addition of $\gamma$-alumina. On one hand, it might be ascribed to the increased acid amount which was brought about by the addition of $\gamma$-alumina. On the other hand, a higher quantity of mesopores might exist in the Catalyst II which was also in favor of the occurrence of the above-mentioned reactions due to the reduction of the diffusion limit.

In theory, more formations of higher molecular hydrocarbons after reaction implied a higher tendency to the increase of aromatics. The obvious increase in the yields of higher molecular hydrocarbons, such as the above-mentioned LPG, gasoline, and diesel, over the Catalyst II probably indicated an increase in the yields of aromatics. To validate this speculation, a comparison chart of the total aromatic yield and single aromatic yields with different carbon numbers over the Catalyst I and Catalyst II is given in Fig. 3.

As expected, total aromatic yields over Catalyst II reached $18.21 \mathrm{wt} \%$, which was obviously higher than that over Catalyst I. Besides, it could also be observed that it was the significant elevation in the yield of $\mathrm{C}_{7}$ aromatic hydrocarbon over the Catalyst II that primarily gave rise to the enhancement of the total aromatic yield. The appreciable increase of $\mathrm{C}_{7}$ aromatic hydrocarbon might be in correlation with the enhanced aromatization of propene and butene. As has been mentioned above, the addition of $\gamma$ alumina gave rise to the decrease of the propene and

Table 1 Product distributions over three kinds of catalysts

\begin{tabular}{lccc}
\hline Items & Catalyst I & Catalyst II & $\gamma$-Alumina \\
\hline Product distribution $(w t \%)$ & & & \\
Conversion & 99.95 & 99.95 & 83.33 \\
$\mathrm{CH}_{4}$ & 0.33 & 1.15 & 2.58 \\
$\mathrm{C}_{2}=$ & 4.23 & 1.82 & 0.05 \\
Dry gas & 4.62 & 3.16 & 2.69 \\
$\mathrm{C}_{3}=$ & 4.12 & 2.53 & 0.07 \\
$\mathrm{C}_{4}=$ & 1.82 & 1.26 & 0.00 \\
LPG & 9.50 & 11.30 & 0.07 \\
Gasoline & 26.39 & 26.49 & 0.00 \\
Diesel & 0.27 & 0.91 & 0.00 \\
Coke & 0.10 & 0.18 & 0.00 \\
Water & 56.25 & 56.25 & 46.86 \\
DME & 2.71 & 1.11 & 28.46 \\
\hline
\end{tabular}




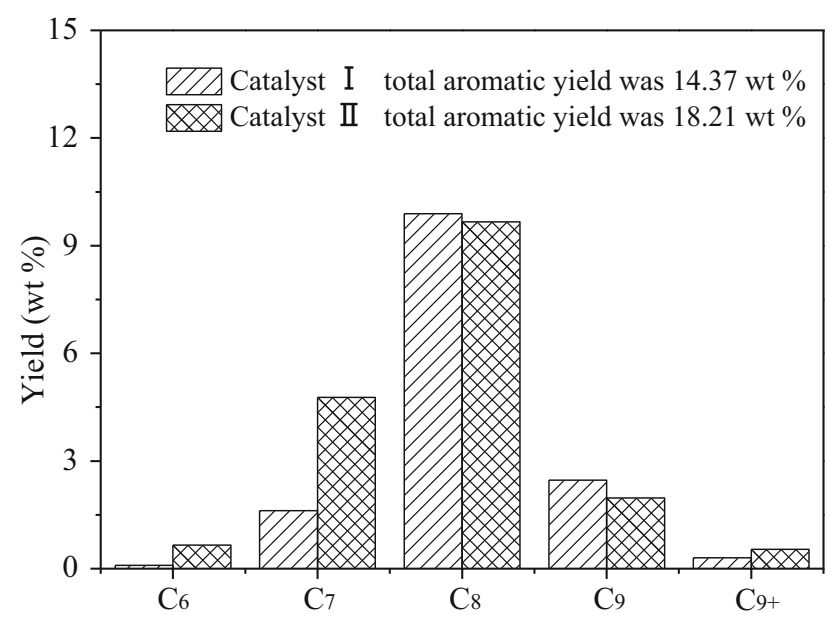

Aromatic hydrocarbons with different carbon numbers

Fig. 3 Comparison for aromatic yields between the Catalyst I and Catalyst II

butene, which indicated that the subsequent aromatization process of the propene and butene was promoted. In contrast, other single aromatic hydrocarbons had a relatively close yield for both catalysts. Kim et al. [35] have reported that alumina had good hydrophilicity, so methanol which was a polar molecular was easily absorbed by the alumina. Similarly, methanol which was a polar molecular was easily absorbed by Catalyst II. In contrary, reaction product had a high nonpolar content that could easily desorb from the surface of Catalyst II, as a result, the reaction depth would be reduced. Therefore, the character of good hydrophilicity might be a key factor in MTA reaction. Above all, despite the fact that $\gamma$-alumina alone could not promote the aromatization of methanol, the introduction of $\gamma$-alumina as an active matrix into the HZSM-5 catalyst could greatly enhance the total aromatic yield, in particular of $\mathrm{C}_{7}$ aromatic hydrocarbon.

\section{Characterization}

The XRD patterns of the Catalyst I, Catalyst II, and $\gamma$ alumina are shown in Fig. 4. It could be seen that the prepared Catalyst II had the characteristic diffraction peaks in common with the $\gamma$-alumina, while the Catalyst I did not. Accordingly, the result above proved that $\gamma$-alumina was successfully incorporated into the Catalyst II, which could be used as a contrast sample in this study.

In view of the results determined by $\mathrm{NH}_{3}$-TPD and adsorption-desorption measurements of nitrogen, the acidity and textural properties for the Catalyst I, Catalyst II, and $\gamma$-alumina are listed in Table 2. According to the data from Table 2, it could be seen that the $\gamma$-alumina had a higher specific surface area and a larger pore volume than

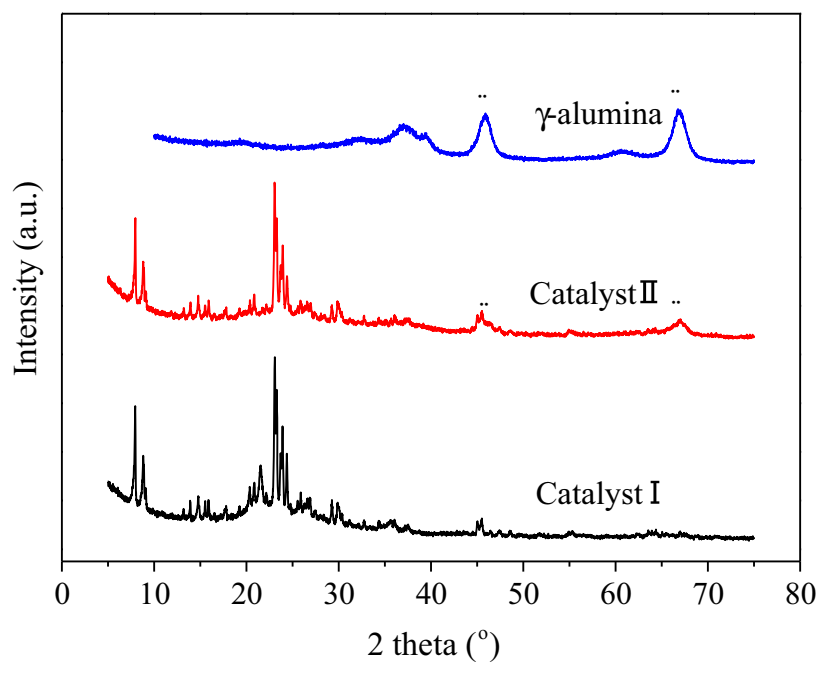

Fig. 4 XRD patterns of the Catalyst I, Catalyst II, and $\gamma$-alumina

Table 2 Textural properties and acidity of the Catalyst I, Catalyst II, and $\gamma$-alumina

\begin{tabular}{llll}
\hline Samples & $\begin{array}{l}\text { Total acid amount } \\
(\mathrm{mmol} / \mathrm{g})\end{array}$ & $\begin{array}{l}\text { Specific surface } \\
\text { area }\left(\mathrm{m}^{2} / \mathrm{g}\right)\end{array}$ & $\begin{array}{l}\text { Pore volume } \\
\left(\mathrm{cm}^{3} / \mathrm{g}\right)\end{array}$ \\
\hline Catalyst I & 0.120 & 118.4 & 0.03 \\
Catalyst II & 0.223 & 172.1 & 0.15 \\
$\gamma$-Alumina & 0.082 & 215.2 & 0.55 \\
\hline
\end{tabular}

those of Catalyst I and Catalyst II, while its total acid amount among the three catalysts was the least. In addition, by comparison with Catalyst I, Catalyst II had a higher acidity and a specific surface area, which might be caused by the introduction of $\gamma$-alumina.

Furthermore, in the light of adsorption-desorption measurements of nitrogen, we could also get the nitrogen adsorption and desorption isotherms for $\gamma$-alumina, Catalyst I, and Catalyst II (shown in Fig. 5). It was very interesting to note that the isotherms for both catalysts exhibited hysteresis loops, which were usually accompanied by the filling and emptying of mesopores by capillary condensation [4]. By comparison, Catalyst II had a far larger hysteresis loop than that of Catalyst I, which indicated that more mesopores were generated in Catalyst II. This result might arise from the way of the incorporation of $\gamma$-alumina. As has been mentioned above, the HZSM-5 catalyst with $\gamma$-alumina was prepared through sol-gel method. Previous reports [36, 37] have demonstrated that mesopores were prone to generate through sol-gel synthesis.

It was generally known that HZSM-5 zeolite itself had a capability of promoting the aromatization of methanol because of its peculiar three-dimensional network that was extremely selective for the formations of aromatics. To 


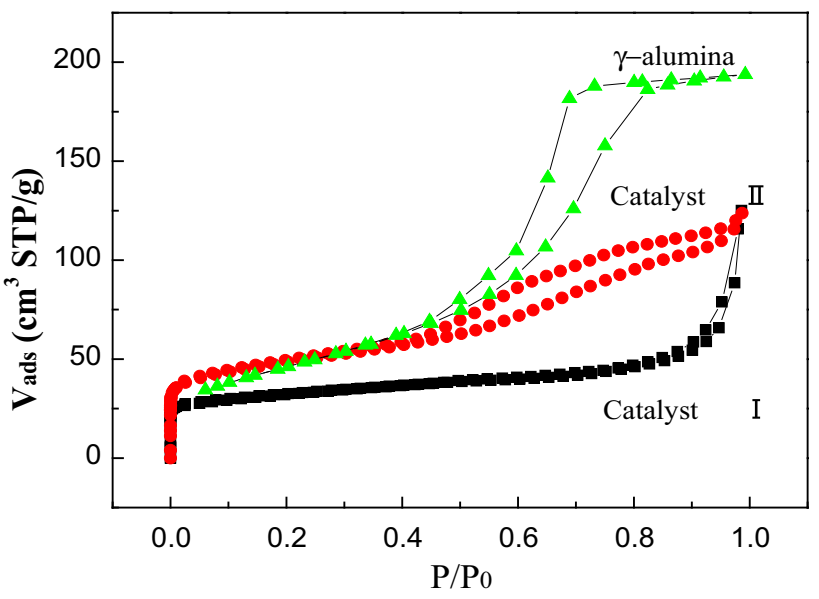

Fig. 5 Nitrogen adsorption and desorption isotherms at $-196{ }^{\circ} \mathrm{C}$ for $\gamma$-alumina, Catalyst I, and Catalyst II

enhance the yields of aromatics, much work specialized in producing mesopores by alkali treatment has been done. Both Zhang et al. [38] and Li et al. [39] have proposed that mesopore generations in the HZSM-5 catalyst cooperating with micropores could significantly elevate the formations of aromatics. On the basis of above analysis, the contact efficiency between methanol and catalyst was enhanced as a result of the increase of surface area, which would enhance the aromatization of intermediates in the subsequent reaction. Mesoporous and macroporous in Catalyst II could decrease the diffusion resistance of final products, it was much easier for high-molecular-weight hydrocarbons to desorb from internal channel surface to outside, then reaction depth would be controlled to reduce coke deposit. Therefore, the existence of mesopores in the Catalyst II might also boost the MTA reaction to an unexpected extent.

Lewis acid and Brönsted acid sites interacted with each other in MTA process through synergistic effect. Surface acid property of catalysts with and without $\gamma$-alumina was analyzed by FT-IR spectra of pyridine adsorption. As shown in Fig. 6, the FT-IR spectra of catalysts were recorded in the range of $1400-1600 \mathrm{~cm}^{-1}$. The bands near $1445 \mathrm{~cm}^{-1}$ and $1550 \mathrm{~cm}^{-1}$ represented Lewis acid and Brönsted acid, respectively. And the band at $1490 \mathrm{~cm}^{-1}$ was characterized to both Lewis and Brönsted acid.

Integral area of Lewis and Brönsted acid were got from FT-IR spectra, and then calculated Lewis acid/ Brönsted acid ratio (Fig. 6). Calculations indicated that, the proportion of Lewis acid sites on Catalyst II was greater than Catalyst I (increased from 0.58 to 0.69). Though the calculation of L/B was semi-quantitative analysis, the effect of the introduction of $\gamma$-alumina in Catalyst II could be proved to a certain extent. The percentage of Lewis acid on catalyst surface increased

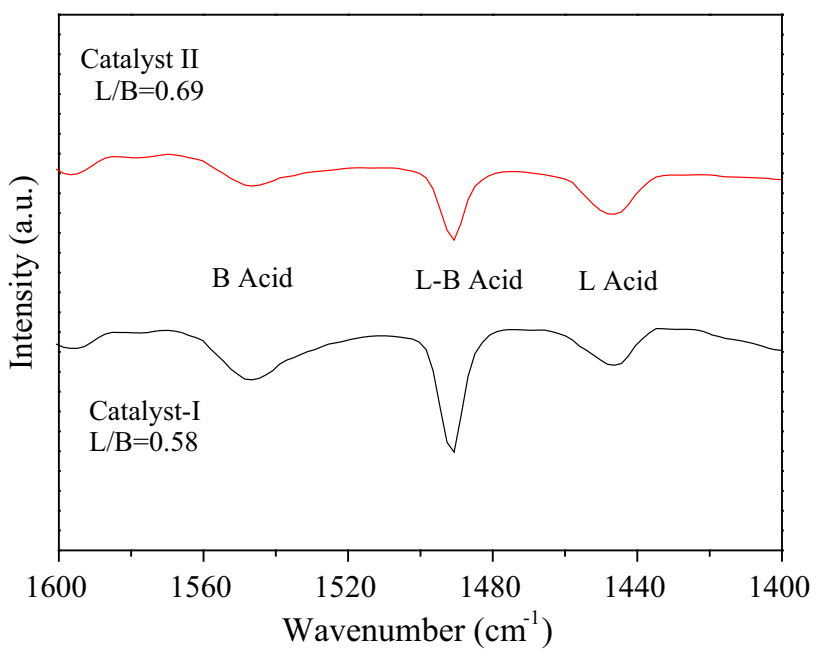

Fig. 6 Pyridine adsorption FT-IR diffuse reflection spectra of Catalyst I and Catalyst II

due to the introduction of $\gamma$-alumina. The combined effect of both Lewis acid and Brönsted acid on catalytic surface was necessary in MTA reaction. In methanol conversion reaction, Brönsted acid played an important role in the oligomerization, circularization, hydrocracking and hydrogen transfer of reaction intermediates, in the meantime, Lewis acid was effective on dehydration of methanol [34] and dehydrogenation of reaction intermediate, such as alkane. As a result of the introduction of $\gamma$-alumina in Catalyst II, the percentage of Lewis acid increased, and then promoted the dehydrogenation of reaction intermediates. Compared to alkane, olefins' aromatization capability was stronger. Combine the product distribution (Table 1) of Catalyst I and II with the data in Fig. 6, the introduction of $\gamma$-alumina increased the opportunities for further dehydrogenation of alkane [40], and improved the catalytic dehydrogenation of aromatic precursors which were produced on Brönsted acid sites (such as $\mathrm{C}_{6}$ and $\mathrm{C}_{7}$ cycloolefins), then changed reaction pathways to produce more intermediates which could participate in the aromatization reaction, finally got high selectivity of aromatic hydrocarbon.

As the $\mathrm{NH}_{3}$-TPD profiles of Catalyst I and Catalyst II are shown in Fig. 7, it was clearly to see that the introduction of $\gamma$-alumina effectively increased the acid site density. Acid site density of Catalyst I and Catalyst II were 0.120 and $0.223 \mathrm{mmol} / \mathrm{g}$, respectively. Meanwhile, desorption peak of Catalyst II shifted to high temperature, which indicated the enhancement of acid strength. According to other literature [40,41], medium strong acid was conductive to the secondary reaction (oligomerization, hydrogen transfer reaction, et al.) of intermediate product (such as olefins), medium strong acid was a final decisive factor in the formation of aromatics. 


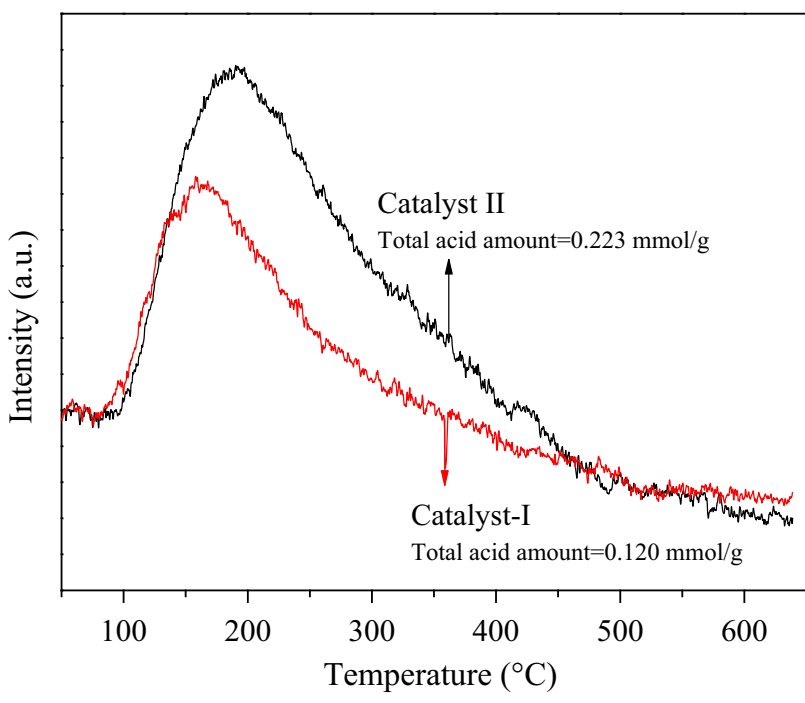

Fig. $7 \mathrm{NH}_{3}$-TPD plots of Catalyst I and Catalyst II

In conclusion, the result from Py-FT-IR spectra and $\mathrm{NH}_{3}$-TPD profiles indicated that both acid site density and acid strength were the affection factors of the rise of aromatics selectivity.

\section{Investigation on the loading amount and loading order of the catalyst with $\gamma$-alumina}

Based on the above-mentioned discussion, we could conclude that $\gamma$-alumina added to HZSM-5 catalyst could considerably contribute to the aromatization of methanol. To further investigate the effect of $\gamma$-alumina on MTA, the loading amount and loading order of the catalyst with $\gamma$ alumina were also observed and studied in this study. With a fixed value of $3 \mathrm{~g}$ of total catalyst loaded at the bottom of the reactor, in the first group, denoted as Group I, the Catalyst I was put in the upper of the catalyst bed with a loading amount of $0.5,1.0,1.5,2.0$, and $2.5 \mathrm{~g}$, respectively. And in the other group, denoted as Group II, the filling order for both catalysts was reversed.

General product distributions involving dry gas, LPG, gasoline, diesel, coke, and $\mathrm{CO}_{\mathrm{x}}$, are exhibited in Fig. 8 . With referencing to Fig. 8, it could be seen that with the decrease of the Catalyst II in the Group I, the yields of dry gas and diesel had an obvious decrease, meanwhile, the total coke deposited on the Catalyst I and Catalyst II, and $\mathrm{CO}_{\mathrm{x}}$ also had a slight drop. In addition, it could also be found that the yield of LPG was raised, while the gasoline fractions changed little. It was not hard to see that the introduced amount of $\gamma$-alumina played a critical role in altering the product distributions for methanol reaction. Moreover, it seemed that with the decrease of $\gamma$-alumina, the process of light hydrocarbons, like LPG compositions, into higher molecular hydrocarbons tended to be suppressed, which might result from the deficiencies of mesopores and acid amount caused by the addition of $\gamma$ alumina. And from the perspective of total yields of higher molecular hydrocarbons, less higher molecular hydrocarbons implied a downward trend in the total aromatic yield.

After adjusting the loading order of the Catalyst II, the product distributions in the Group II displayed some similarities with those obtained in the Group I. For example, the yields of diesel, coke and $\mathrm{CO}_{\mathrm{x}}$ still increased with the increasing of the Catalyst II. However, there were also some differences. The yield of dry gas went down with the increasing of Catalyst II, which totally differed from the variation trend of the dry gas in the Group I. It indicated that the formation of dry gas had no direct relationship with the addition of $\gamma$-alumina. In addition, unlike the essentially invariant yield of the gasoline in the Group I, the gasoline content in the Group II showed an upward trend with the increase of Catalyst II, which demonstrated that the formation of gasoline had a positive correlation with the introduced amount of $\gamma$-alumina when methanol first passed through Catalyst II. With regard to the coke deposited on both catalysts, it had a remarkable growth with the increasing Catalyst II, which indicated that it was much easier to generate the precursors of the coke with the Catalyst II in the upper of the catalyst bed.

Similar to the variation tendency of the coke, the $\mathrm{CO}_{\mathrm{x}}$ including $\mathrm{CO}$ and $\mathrm{CO}_{2}$, also had an appreciable increase with the increase of the Catalyst II in the Group II. To the best of our knowledge, the formation of $\mathrm{CO}_{\mathrm{x}}$ mainly originated from three pathways which was consist of direct pyrolysis of methanol, transformation reaction of methanol with steam, and methanation reaction of methanol. The reaction temperature for two groups of experiments was same, while the direct pyrolysis of methanol was in correlation with reaction temperature, thus the effect from direct pyrolysis of methanol could be ruled out. We could suspect that it was the latter two factors that predominantly gave rise to the increase of $\mathrm{CO}_{\mathrm{x}}$.

Considering the above-mentioned changes of general product distributions caused by the loading amount and loading order of the Catalyst II, we could suspect that the generations of aromatics must be affected, as well. Therefore, a comparison table about the total aromatic yields for both groups is given in Table 3 for the purpose of investigating the variation trends of aromatics.

According to Table 3, it could be observed that despite the filling order, with the increase of the Catalyst II, the total aromatic yields for both groups showed an upward trend. It further proved that the formations of aromatics had a direct relationship with the increase of mesopores and acidity of the catalyst because of the addition of $\gamma$-alumina. However, there was also a slightly larger discrepancy in the aromatic yields for both groups when the loading amount 

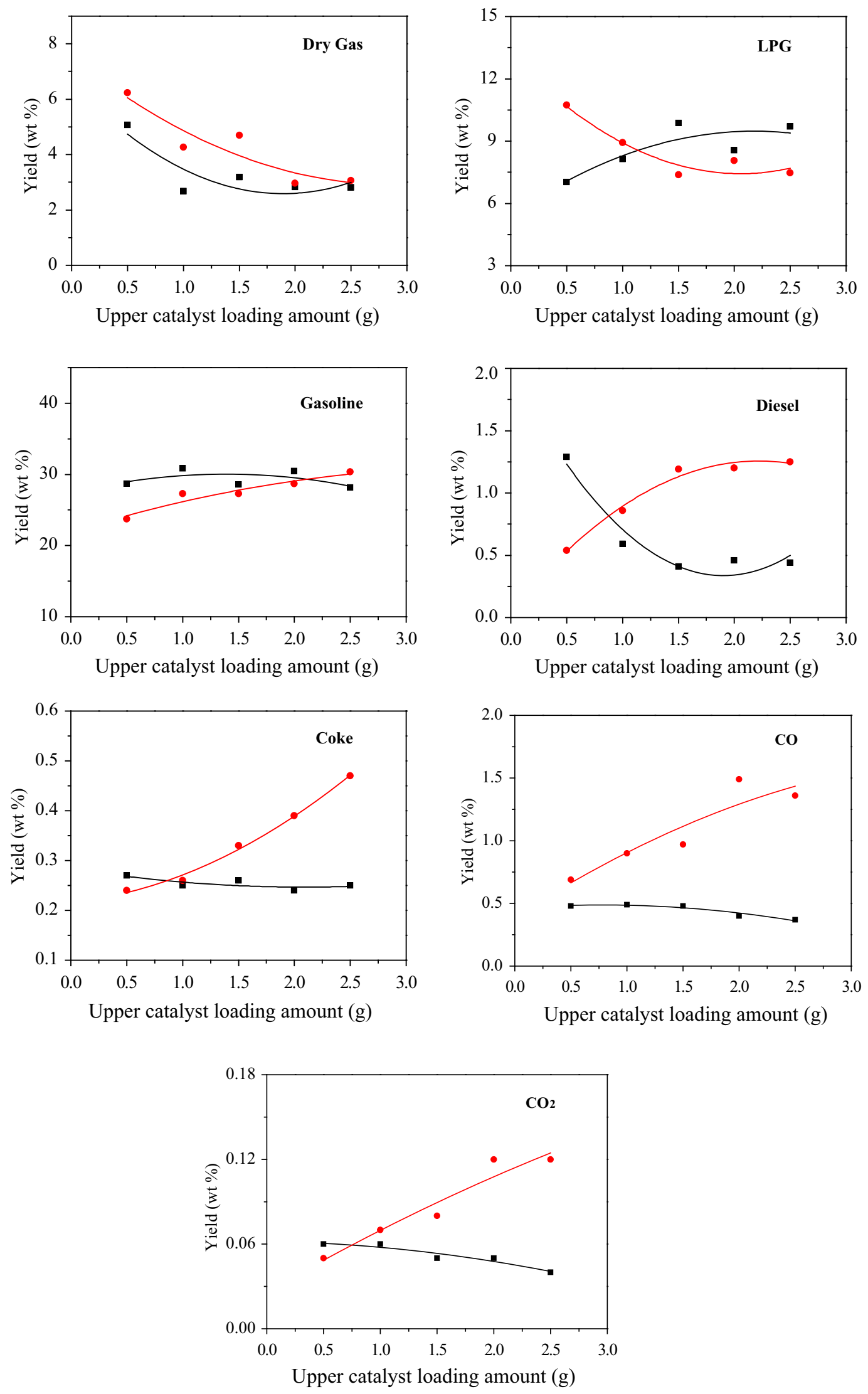
4Fig. 8 General product distributions for investigation on the loading amount and loading order of the catalyst with $\gamma$-alumina (filled square Catalyst I in the upper, filled circle Catalyst II in the upper)

of the Catalyst II held the same. It indicated that the loading order of the Catalyst II also exerted an effect on the productions of aromatics. Besides, it could also be seen that the Group II had a larger range of aromatic yield from 12.28 to 20.27 wt\% compared with that of the Group I. The reason for this case was probably in connection with the intermediate products formed after the methanol passing through the upper catalyst.

To further investigate the formations of aromatics, a comparison graph of gasoline compositions for both groups is given in Fig. 9. It was very interesting to find that the gasoline compositions for both groups had a similar variation trend. As could be seen from Fig. 9, the increased selectivity towards aromatics was at the expense of paraffins, olefins, and naphthenes. It was generally known that MTA reaction was an acid-catalyzed process which included a series of reactions such as olefinic oligomerization, cracking, cyclization, and hydrogen transfer. With referencing to Fig. 9, with the increase of the Catalyst II, the selectivity towards olefins had a downward trend for both groups, which indicated that the addition of $\gamma$-alumina might promote the subsequent aromatization process of the olefins.

Table 4 gave the variation trends of the light alkenes. On the basis of the decreasing yields of the propene and butene with the increasing Catalyst II, it could be suspected that $\gamma$-alumina could enhance the oligomerization of light alkenes. Furthermore, combined with the downward trend in the naphthenes, $\gamma$-alumina could also promote the final aromatization of naphthenes. Zhang et al. [42] have reported that Lewis acid was conductive to the dehydrogenation of naphthenes, and it was generally recognized that the introduction of $\gamma$-alumina mainly added to the amount of Lewis acid in the HZSM-5-based catalyst. Therefore, with the increase of the Catalyst II, more Lewis acid would exist, thus contributing to the dehydrogenation of naphthenes and in turn boosting the subsequent formations of aromatics.
As for the effect of the loading order of the Catalyst II on the gasoline compositions, it can be observed that the gasoline compositions had an appreciably larger variation range when methanol first passed through the Catalyst II. Moreover, among the gasoline compositions, the variations of the olefins and aromatics were particularly prominent. The selectivity towards olefins for the Group I and Group II ranged from 13.08 and 8.59-16.49 and $18.34 \mathrm{wt} \%$, respectively. And the aromatic selectivity for both groups ranged from 54.65 and 51.74-64.73 and $66.84 \mathrm{wt} \%$, respectively. The above-mentioned changes demonstrated that at lower loading amount of the Catalyst II, it was not beneficial for the formations of olefins or subsequent aromatization process of olefins when methanol first passed through the Catalyst II. However, with the increasing loading amount of the Catalyst II, the aromatization of methanol in the Group II could get a significant promotion.

With regard to the effect of the loading amount and loading order of the Catalyst II on the single aromatic hydrocarbons, it was also investigated (shown in Fig. 10). On one hand, regardless of the loading order of the Catalyst II, all single aromatic hydrocarbons increased gradually with the increase of the Catalyst II. They were in agreement with the variation trend of the total aromatic yields for both groups. Besides, previous research [35] has reported that $\gamma$-alumina had a hydrophilic property. Therefore, the addition of $\gamma$-alumina was bound to adsorb the methanol much more readily during the reaction, which greatly increased the possibility of the contact between methanol and HZSM-5 catalyst and in turn boosted the subsequent aromatization of methanol. However, there was also a discrepancy between the two groups. In contrast with the single aromatic hydrocarbons in the Group I, the single aromatic hydrocarbons in the Group II showed a larger variation change.

On the other hand, it could be seen that the primary single aromatic hydrocarbons formed were $\mathrm{C}_{8}$ (ethylbenzene and xylenes) aromatic hydrocarbons followed by $\mathrm{C}_{7}$ (toluene) and $\mathrm{C}_{9}$ (trimethylbenzenes) aromatic hydrocarbons. Considering the limited pore size of HZSM-5-based catalyst, larger aromatic hydrocarbons such as $\mathrm{C}_{9}{ }^{+}$aromatic hydrocarbons (mainly including $\mathrm{C}_{10}$ and $\mathrm{C}_{11}$

Table 3 Total aromatic yields for the Group I and Group II

\begin{tabular}{|c|c|c|c|c|}
\hline 0.5 & 1.0 & 1.5 & 2.0 & 2.5 \\
\hline 18.58 & 18.87 & 16.73 & 17.34 & 15.37 \\
\hline 12.28 & 15.94 & 15.32 & 18.60 & 20.27 \\
\hline
\end{tabular}

Total aromatic yield (wt\%)

Group I 

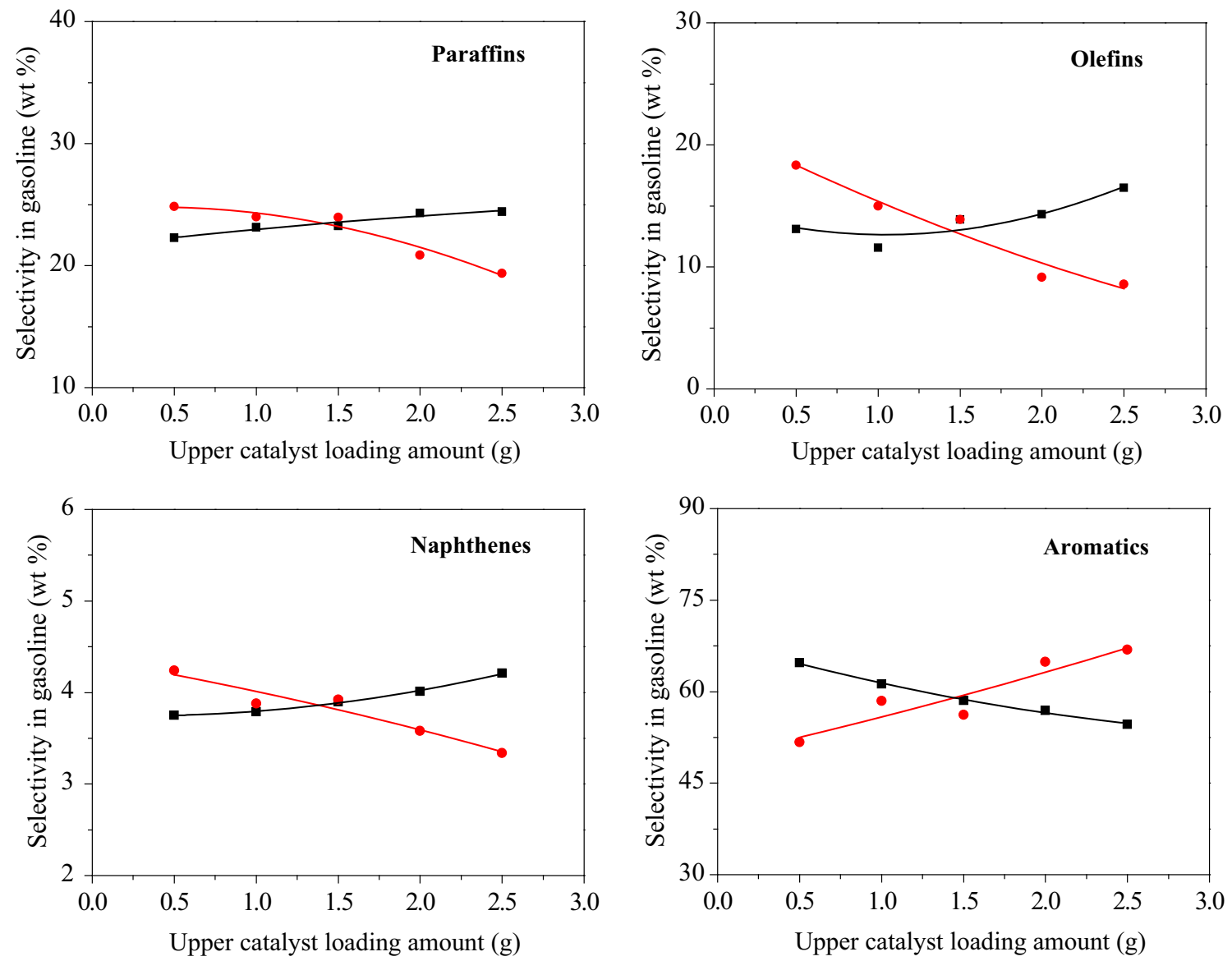

Fig. 9 Gasoline compositions for the Group I and Group II (filled square Catalyst I in the upper, filled circle Catalyst II in the upper)

Table 4 Yields of the propene and butene for the Group I and Group II

\begin{tabular}{|c|c|c|c|c|c|}
\hline \multirow[t]{2}{*}{ Yield (wt\%) } & \multicolumn{5}{|c|}{ Catalyst loading amount in the upper $(\mathrm{g})$} \\
\hline & 0.5 & 1.0 & 1.5 & 2.0 & 2.5 \\
\hline \multicolumn{6}{|l|}{ Group I } \\
\hline $\mathrm{C}_{3}=$ & 2.99 & 2.37 & 3.00 & 2.61 & 3.31 \\
\hline $\mathrm{C}_{4}=$ & 0.75 & 0.81 & 1.18 & 0.99 & 1.30 \\
\hline \multicolumn{6}{|l|}{ Group II } \\
\hline $\mathrm{C}_{3}=$ & 3.68 & 2.70 & 3.01 & 1.90 & 1.97 \\
\hline $\mathrm{C}_{4}=$ & 1.70 & 1.35 & 0.85 & 0.81 & 0.71 \\
\hline
\end{tabular}

aromatic hydrocarbons) were difficult to generate. Even if $\mathrm{C}_{9}{ }^{+}$aromatic hydrocarbons could form in the pore volume, considering the diffusion limitations caused by the confined pore diameter, they could not pass through the channel readily and then came out of the catalyst. The above-mentioned restriction effect could be reflected by the variation trends of $\mathrm{C}_{9}{ }^{+}$aromatic hydrocarbons with the increasing loading amount of the Catalyst II. The more loading amount of the Catalyst II indicated more mesoporous existence, the more $\mathrm{C}_{9}{ }^{+}$aromatic hydrocarbons formed. With regard to the rather low selectivity towards $\mathrm{C}_{6}$ aromatic hydrocarbon, Tian et al. [9] have proposed that methanol had a high capability of alkylation. Thus, the alkyls formed during the reaction could easily add to benzene rings through electrophilic attack, and as a result, xylenes and trimethylbenzenes were formed. 

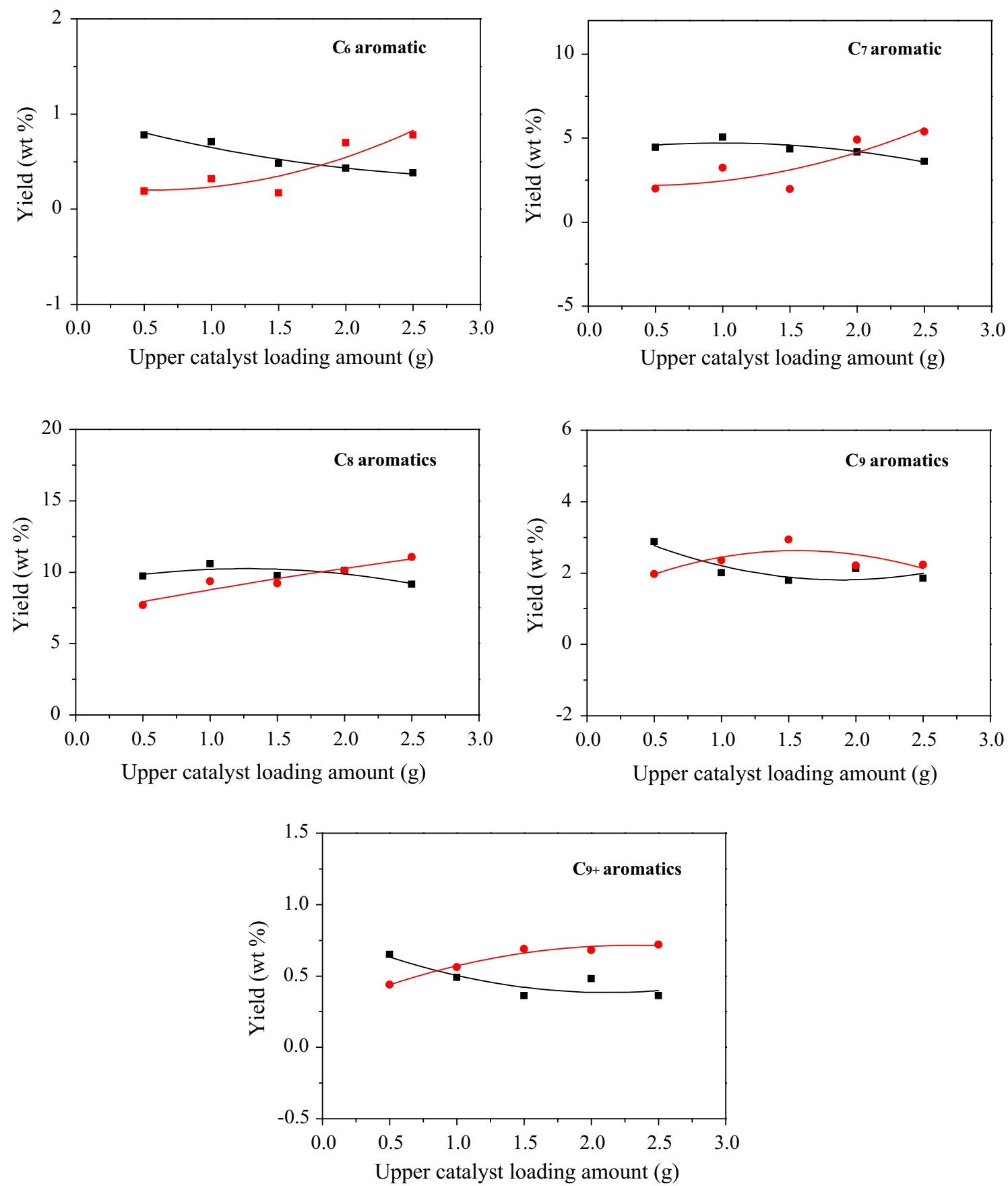

Fig. $10 \mathrm{C}_{6}-\mathrm{C}_{9}{ }^{+}$aromatic yields for the Group I and Group II (filled square Catalyst I in the upper, filled circle Catalyst II in the upper)

\section{Conclusions}

The introduction of $\gamma$-alumina to the HZSM- 5 catalyst by the sol-gel method could produce more mesopores in the catalyst. Meanwhile, the acid amount of the catalyst was also raised, as well as the percentage of Lewis acid sites on catalyst surface. According to the separate reaction performance of the catalyst with/without $\gamma$-alumina, and $\gamma$ alumina, the addition of $\gamma$-alumina could considerably promote the aromatization of methanol with the total aromatic yield reaching $18.21 \mathrm{wt} \%$ from $14.31 \mathrm{wt} \%$. And the increased amount of the total aromatic yield mainly originated from the increase of $\mathrm{C}_{7}$ aromatic hydrocarbon. However, $\gamma$-alumina alone could merely convert methanol to DME with a minor quantity of gaseous hydrocarbon products. In addition, the general product distributions also changed after the $\gamma$-alumina was introduced. Except the dry gas, the yields of LPG, gasoline, diesel, and coke had a 
relatively higher value over the catalyst with $\gamma$-alumina than those over the catalyst without $\gamma$-alumina.

With respect to the effect of the loading amount and loading order of the catalyst with $\gamma$-alumina, it could be seen that the general product distributions were affected to a certain extent. The result showed that the formations of dry gas had no direct relationship with the loading order of the catalyst with $\gamma$-alumina. In contrast with the mild change of the gasoline in the Group I, the gasoline in the Group II had a sharper increase with the increasing catalyst with $\gamma$-alumina. And the coke deposited on the catalyst demonstrated that it was much easier to form the precursors of the coke when methanol first passed through the catalyst with $\gamma$-alumina. In addition, methanol first passed through the catalyst $\gamma$-alumina could enhance a markedly larger improvement of $\mathrm{CO}_{\mathrm{x}}$.

Moreover, the loading amount and loading order of the catalyst with $\gamma$-alumina played a vital role in the formations of aromatics. Despite the loading order of the catalyst with $\gamma$-alumina, the total aromatic yields for both groups had an upward trend with the increase of the catalyst with $\gamma$-alumina. And the gasoline compositions for both groups demonstrated that the increased aromatics were at the expense of paraffins, olefins, and naphthenes. Besides, be compared with the Group I, the Group II had a larger range of aromatic yield from 12.28 to $20.27 \mathrm{wt} \%$. Meanwhile, all single aromatic hydrocarbons went up gradually with the increasing catalyst with $\gamma$-alumina. Among the single aromatic hydrocarbons formed, the $\mathrm{C}_{8}$ aromatic hydrocarbons were the maximum followed by $\mathrm{C}_{7}$ and $\mathrm{C}_{9}$ aromatic hydrocarbons. Due to the limited pore structure and methylation of methanol, the formations of $\mathrm{C}_{9}{ }^{+}$and $\mathrm{C}_{6}$ aromatic hydrocarbons were relatively lower. With respect to the effect of the loading order of the catalyst with $\gamma$ alumina on the single aromatic hydrocarbons, the single aromatic hydrocarbons in the Group II showed larger variations than those in the Group I.

Acknowledgments The authors acknowledge the financial support provided by the National Natural Science Foundation of China (No. 21406270) and the Livelihood Program of Qingdao, China (No. 13-13-126-nsh).

Open Access This article is distributed under the terms of the Creative Commons Attribution 4.0 International License (http:// creativecommons.org/licenses/by/4.0/), which permits unrestricted use, distribution, and reproduction in any medium, provided you give appropriate credit to the original author(s) and the source, provide a link to the Creative Commons license, and indicate if changes were made.

\section{References}

1. Li YQ, Bai EZ, Duan QW (2005) Recent progress of aromatics production technologies. Petrochem Technol 34:309-315
2. Choi M, Na K, Kim J et al (2009) Stable single-unit-cell nanosheets of zeolite MFI as active and long-lived catalysts. Nature 461:246-249

3. Kim J, Choi M, Ryoo R (2010) Effect of mesoporosity against the deactivation of MFI zeolite catalyst during the methanol-to-hydrocarbon conversion process. J Catal 269(1):219-228

4. Bjørgen M, Joensen F, Spangsberg Holm M et al (2008) Methanol to gasoline over zeolite H-ZSM-5: improved catalyst performance by treatment with $\mathrm{NaOH}$. Appl Catal A 345(1):43-50

5. Chang CD, Kuo JC, Lang WH et al (1978) Process studies on the conversion of methanol to gasoline. Ind Eng Chem Process Des Dev 17(3):255-260

6. Ono Y (1992) Transformation of lower alkanes into aromatic hydrocarbons over ZSM-5 zeolites. Catal Rev Sci Eng 34(3):179-226

7. Seddon D (1990) Paraffin oligomerisation to aromatics. Catal Today 6(3):351-372

8. Yao JH, Le Van Mao R, Dufresne L (1990) Conversion of n-butane into BTX aromatics on new hybrid catalysts. Appl Catal 65(2): $175-188$

9. Tian T, Qian WZ, Sun YJ et al (2009) Aromatization of methanol on Ag/ZSM-5 catalyst. Mod Chem Ind 29:55-58

10. Zeng D, Yang J, Wang J et al (2007) Solid-state NMR studies of methanol-to-aromatics reaction over silver exchanged HZSM-5 zeolite. Microporous Mesoporous Mater 98(1-3):214-219

11. Inoue Y, Nakashiro K, Ono Y (1995) Selective conversion of methanol into aromatic hydrocarbons over silver-exchanged ZSM-5 zeolites. Microporous Mater 4(5):379-383

12. Tian T, Qian WZ, Tang XP et al (2010) Deactivation of Ag/ZSM5 catalyst in the aromatization of methanol. Acta Phys Chim Sin 26(12):3305-3309

13. Qiu P, Lunsford JH, Rosynek MP (1998) Characterization of Ga/ ZSM-5 for the catalytic aromatization of dilute ethylene streams. Catal Lett 52(1-2):37-42

14. Freeman D, Wells RP, Hutchings GJ (2001) Methanol to hydrocarbons: enhanced aromatic formation using a composite $\mathrm{Ga}_{2} \mathrm{O}_{3}$-H-ZSM-5 catalyst. Chem Commun 18:1754-1755

15. Freeman D, Wells RP, Hutchings GJ (2001) Conversion of methanol to hydrocarbons over Ga2O3/H-ZSM-5 and Ga2O3/ WO3 catalysts. J Catal 205(2):358-365

16. Freeman D, Wells RP, Hutchings GJ (2002) Methanol to hydrocarbons: enhanced aromatic formation using composite group 13 oxide/H-ZSM-5 catalysts. Catal Lett 83(3-4):217-225

17. She LQ, Wang DC, Li XW et al (1994) The states of zinc in ZnZSM-5 zeolites and their catalysis. Acta Phys Chim Sin 10:301-305

18. Gui JZ, Zhang XT, Hu ZD et al (2003) A study of n-hexane aromatization on the $\mathrm{ZnNi} / \mathrm{HZSM}-5$ catalyst. J Lanzhou Univ Nat Sci 39(5):61-65

19. Shurong Z, Jinglong H, Dahua T (2001) Study on dehydrocyclization and aromatization process over ZnHZSM-5 catalyst. Petrol Process Petrochem (China) 32(6):60-63

20. Chang CD, Silvestri AJ (1977) The conversion of methanol and other O-compounds to hydrocarbons over zeolite catalysts. J Catal 47(2):249-259

21. Giannetto G, Monque R, Galiasso R (1994) Transformation of LPG into aromatic hydrocarbon and hydrogen over zeolite catalysts. Catal Rev Sci Eng 36(2):271-304

22. Biscardi JA, Iglesia E (1999) Reaction pathways and rate-determining steps in reactions of alkanes on H-ZSM5 and Zn/H-ZSM5 catalysts. J Catal 182(1):117-128

23. Ono Y, Adachi H, Senoda Y (1988) Selective conversion of methanol into aromatic hydrocarbons over zinc-exchanged ZSM5 zeolites [J]. J Chem Soc Faraday Trans 1 Phys Chem Condens $\mathrm{Ph}$ 84(4):1091-1099 
24. Berndt H, Lietz G, Völter J (1996) Zinc promoted H-ZSM-5 catalysts for conversion of propane to aromatics II. Nature of the active sites and their activation. Appl Catal A 146(2):365-379

25. Jianchao X, Dongsen M, Qingiing C et al (2004) Bifunctional catalysts for direct synthesis of dimethyl ether from syngas. Petrochem Technol 8:020

26. Han G, Yue Y, Ding YR (1991) The acid base synergism on $\gamma$ $\mathrm{Al} 2 \mathrm{O} 3$ in $\mathrm{CO}+\mathrm{H} 2$ catalysts. Nanjing Univ 27:700-705

27. Li JL, Zhang XG, Inui $T$ (1996) Improvement in the catalyst activity for direct synthesis of dimethyl ether from synthesis gas through enhancing the dispersion of $\mathrm{CuO} / \mathrm{ZnO} / \gamma-\mathrm{Al} 2 \mathrm{O} 3$ in hybrid catalysts. Appl Catal A 147(1):23-33

28. Ge QJ, Huang YM, Zhang TL (1996) Bifunctional catalysts for direct synthesis of dimethyl ether from synthesis gas I. Study on the preparation method. Nat Gas Chem Ind (C1 Chem Technol) 21(5):19-22

29. Qi GX, Zheng XM, Fei JH et al (2001) A novel catalyst for DME synthesis from $\mathrm{CO}$ hydrogenation: 1. Activity, structure and surface properties. J Mol Catal A Chem 176(1):195-203

30. Omata K, Watanabe Y, Umegaki T et al (2002) Low-pressure DME synthesis with Cu-based hybrid catalysts using temperature-gradient reactor. Fuel 81(11):1605-1609

31. Baumann TF, Gash AE, Chinn SC et al (2005) Synthesis of highsurface-area alumina aerogels without the use of alkoxide precursors. Chem Mater 17(2):395-401

32. Yaripour F, Baghaei F, Schmidt IB et al (2005) Catalytic dehydration of methanol to dimethyl ether (DME) over solid-acid catalysts. Catal Commun 6(2):147-152

33. Dongsen M, Weimin Y, Bin Z et al (2006) Modification of alumina and its application in the direct synthesis of dimethyl ether from syngas. Chin J Catal 27(6):515-521
34. Youxie ZBLQX, Wei Z (1986) Reaction mechanism of methanol to hydrocarbons on HZSM-5. J Fuel Chem Technol 4:9-16

35. Kim SD, Baek SC, Lee YJ et al (2006) Effect of $\gamma$-alumina content on catalytic performance of modified ZSM-5 for dehydration of crude methanol to dimethyl ether. Appl Catal A 309(1):139-143

36. Jia MJ, Liu G, Zhang M et al (2008) Advances in the synthesis of mesoporous materials by sol-gel method. J Nat Sci Heilongjiang Univ 25:759-764

37. Elaloui E, Pierre AC, Pajonk GM (1997) Influence of the sol-gel processing method on the structure and the porous texture of nondoped aluminas. J Catal 166(2):340-346

38. Zhang GC, Bai T, Qu WT et al (2013) Aromatization of methanol II. Catalytic activity of $\mathrm{NaOH}$ treated HZSM-5 catalyst. Petrochem Technol 42:265-270

39. Li Y, Liu S, Zhang Z et al (2008) Aromatization and isomerization of 1-hexene over alkali-treated HZSM-5 zeolites: improved reaction stability. Appl Catal A 338(1):100-113

40. Haag WO, Lago RM, Weisz PB (1981) Transport and reactivity of hydrocarbon molecules in a shape-selective zeolite. Faraday Discuss Chem Soc 72:317-330

41. Nayak VS, Choudhary VR (1984) Effect of hydrothermal treatments on acid strength distribution and catalytic properties of HZSM-5. Appl Catal 10(2):137-145

42. Zhang L, Wu F, Lu B et al (2004) Aromatization of ethylene over metal supported HZSM-5 catalysts. Huaxue Shijie (Chem World) $7: 353-356$ 